\title{
"Raça", Sexualidade e Saúde: Discutindo Fronteiras e Perspectivas
}

O Brasil vem assistindo nos últimos anos - com um ar meio estupefato, é preciso dizer - a um debate público, inédito no país, sobre questão "racial" e "racismo", miscigenação e nação, sistema de ação afirmativa, cotas e políticas públicas com base na diferenciação por "cor/raça" dos indivíduos. As áreas de educação e saúde se destacaram nesse cenário pela sua atuação e mobilização. Sob holofotes nessa cena está a Universidade do Estado do Rio de Janeiro, que implementou um sistema pioneiro de cotas, sem a precedência de qualquer debate no interior da comunidade universitária. De fato, nesse campo (assim como em muitos outros, os quais não cabe mencionar nesta apresentação), estamos navegando enquanto construímos o barco.

Uma questão recorrente no debate se refere ao conceito de "raça/ cor" em vigência no Brasil. Além disso, a propalada miscigenação brasileira, tão valorizada quanto criticada, adquiriu novas dimensões. Questões sobre quem pode ser considerado negro, pardo ou branco, sobre o que é "raça" e qual o seu estatuto científico e social, sobre miscigenação, "racismo", bem como sobre a possibilidade e os perigos de se criar instâncias reguladoras e fiscalizadoras das classificações "raciais" daqueles que se candidatam aos sistemas de cotas, têm ocupado não somente as páginas dos principais jornais do país como, igualmente, mobilizado acalorados debates nos meios acadêmico e ativista e entre acadêmicos e ativistas.

No Brasil, "raça", sexualidade, gênero e saúde aparecem como campos de conhecimento separados, mas as recentes mudanças mencionadas vêm problematizando essas e outras fronteiras. Nesse sentido, é preciso enfrentar duas questões de suma relevância para uma compreensão mais precisa dessa interseccionalidade: o que é "racismo"? O que engendra a idéia de "raça"? 
O antropólogo Claude Lévi-Strauss produz uma resposta persuasiva, nesse sentido. Trata-se de uma doutrina que já adquiriu, em outras épocas, status científico e determina que: 1) existe uma correlação entre patrimônio genético e aptidões morais e intelectuais; 2) esse patrimônio caracteriza os grupos "raciais"; 3) os grupos "raciais" são hierarquizados de acordo com o maior ou menor desenvolvimento desse patrimônio; 4) essa hierarquia autorizou "raças" supostamente civilizadas e superiores a controlar, explorar e mesmo destruir as inferiores (Cf. LÉVI-STRAUSS \& ERIBON, 1990, p. 194-195).

Já que "racismo" pode ser concebido como uma doutrina (ou uma ideologia, se preferirem), podemos concluir que antes de estarmos lidando com um conceito, estamos lidando com uma representação "nativa", ou seja, sempre construída em um certo contexto social, cultural e histórico específico e que varia de acordo com épocas e lugares (Cf. FRY, 1996, entre outros).

Qual a relevância dessa afirmação? Se desejamos entender como o "racismo" se manifesta, faz-se necessário entender e relativizar a "realidade do racismo". Em resumo, essa "realidade" é fundamentalmente diferente no Brasil, na África do Sul e nos Estados Unidos, por exemplo. A começar pelo próprio sistema de classificação de "cor/raça".

Como destaca o antropólogo Oracy Nogueira, no Brasil temos um sistema de classificação de "cor/raça" baseado predominantemente na aparência: são os traços fenotípicos que contam na classificação "racial" das pessoas, algo que, como desenvolvi em outro lugar (Moutinho, 2004a), com base nas idéias de Thales de Azevedo (1975), envolve não somente aparência mas a manipulação estética da cor - constrói-se a negritude e a brancura. Neste sentido, contam outros aspectos que são o contexto, sinais de status (e seu uso e manipulação) e, por fim, o aspecto relacional. Em resumo, "cor/ raça" varia de acordo com o contexto e os sinais de prestígio/estigma envolvidos (pode-se ser mais ou menos negro/branco de acordo com o local de referência, como por exemplo, áreas nobres, empobrecidas e/ou favelizadas; escola; baile funk, show de rock, pagode etc.) e é relacional, no sentido de que, além de todos os elementos assinalados, a classificação por "cor/raça" depende de com quem se está travando relações naquele momento. Essa multiplicidade implica, igualmente, um "racismo" que possui diferenciadas faces e não menos perversas formas de atuação.

No Brasil, pode-se dizer que há, grosso modo, três grandes eixos classificatórios: 1) o oficial - aquele utilizado pelo IBGE, que trabalha há 120 
anos com as mesmas categorias de "cor/raça", que são preto, branco, pardo, amarelo e indígena; 2) o modo múltiplo - o mais popular, que opera uma variada gama de classificações como moreninho, marrom bombom, preto mesmo, branco mesmo, aguado, leitoso, canelinha, entre outros; 3 ) modo bipolar-negro/branco, que possui dois grandes usos: militante (que além das categorias negro e afrobrasileiro, agora, difundiu o afro-descendente) e o popular, que é situacional e complementar ao múltiplo: um auxílio para maior definição na classificação (Cf. FRY, 1996).

Nos EUA, a ênfase recai na origem ou ascendência - de modo que, a princípio, o que conta é a ancestralidade e não a aparência. O sistema americano restringiu, a partir da década de 20 , seu sistema classificatório, eliminando do Censo as categorias para mestiços. Esse país teve o "racismo" na constituição até a década de 60. A África do Sul, apenas para iluminar esse ponto de modo contrastivo, também teve o "racismo" integrando a constituição com o apartheid, instalado em 1948, mas manteve a categoria mestiço - o coloured - como uma classificação oficial e ideológica. Em processos criminais contra casais e amantes "inter-raciais", o coloured aparece como um problema classificatório: não era definido apenas pela aparência ou origem (estas poderiam ser dribladas), mas também pela convivência (Cf. MOUTINHO, 2004 a e b).

Conhecer a lógica das classificações locais é relevante, igualmente, para acompanharmos todo um longo percurso de mudanças sociais e políticas ao qual as categorias de "cor" e "raça" estão, de fato, articuladas. "Raça", gênero e sexualidade são aspectos de fundamental importância no acesso a bens, status e ocupação/emprego e, igualmente, tanto no cuidado de si quanto no acesso ao sistema de saúde. Mas esses três elementos não devem ser compreendidos como um conjunto de sujeições combinadas (Cf. STOLCKE, 1991 e MOUTINHO, 2004a e 2002). Trata-se, em outras palavras, de uma inter-relação, permeável e modificada pelas estruturas de poder e, sobretudo, pelos símbolos de prestígio social, agregados às referências de gênero, "raça" e sexualidade. Ter em mente essas dimensões talvez nos auxilie a compreender alguns dos sentidos e significados relativos a "raça", "cor" e "racismo", gênero e sexismo - e suas complexas dimensões e mais maléficas atuações.

Este número da Revista Physis está inscrito nesse campo, abordando, porém, algumas de suas faces menos explícitas e investindo em áreas onde pairam dúvidas que precisam ser colocadas em perspectiva. Para contribuir para o debate, foram convidados cinco pesquisadores que pudessem fornecer 
ao leitor de Physis um amplo espectro de temas intercruzados (e operando) com uma certa idéia de "raça" e "racismo".

Josué Laguardia abre a coletânea apresentando um extenso mapeamento da idéia de "raça" em pesquisas na área de saúde. Ao recuperar o percurso histórico da produção de conhecimento sobre o tema e cotejá-la com o debate atual, tem-se a clara dimensão da necessidade (e dos percalços) de se intensificar o debate nesse âmbito. $\mathrm{O}$ autor nos convida a penetrar no labirinto da produção de novos e velhos "racismos". Percorrendo seu texto, é possível acompanhar a transformação à qual a idéia de "raça" vem sendo submetida a partir da produção de novos poderes e saberes. São novas identidades e práticas que promovem o que Rabinow (1996) nomeou de passagem do biopoder clássico de Foucault para a biossociabilidade.

Enquanto fecho esta apresentação, chega-me às mãos um encarte que tem apoio de várias entidades, como UNFPA, Unicef, Unesco, UNDCP, Unaids e Unifem, intitulado Política Nacional de Saúde da População Negra: uma questão de equiidade. Além de fornecer dados e subsídios para que se conheça o perfil epidemiológico de grupos "raciais" e étnicos, a introdução do trabalho coloca o leitor frente a duas classificações das doenças e agravos que atingem a população negra: as "geneticamente determinadas - anemia falciforme e deficiência de glicose 6-fosfato desidrogenase; ou dependentes de elevada frequiência de genes responsáveis pela doença ou a ela associadas - hipertensão arterial e diabetes mellitus" e as "adquiridas, derivadas de condições socioeconômicas desfavoráveis - desnutrição, mortes violentas, mortalidade infantil elevada, abortos sépticos, anemia ferropriva, DST/Aids, doenças do trabalho, transtornos mentais resultantes da exposição ao "racismo" e ainda transtornos derivados do abuso de substâncias psicoativas, como o alcoolismo e a toxicomania" (PNUD, 2004, p. 7-8). Vê-se nesse texto uma complexa combinação de distintas racionalidades: as consequiências das desigualdades sociais que incidem sobre a qualidade de vida de grupos discriminados com base na "cor", "raça" e etnia e o agrupamento de indivíduos em torno das classificações produzidas pela nova genética. $\mathrm{O}$ artigo de Laguardia auxilia o leitor de Physis a percorrer e compreender esse universo.

Rosely Costa nos lança a um pólo oposto daquele abordado no texto que o antecede. Ao tratar de "raça" e tecnologias reprodutivas, traz o leitor para um universo que parece infenso ao debate atual sobre o tema. A autora penetra nos labirintos da construção e reprodução da semelhança, mostrando 
como os critérios "raciais" incidem na reprodução assistida, operando a manutenção "do mesmo".

$\mathrm{O}$ artigo de Jane Beltrão abre uma perspectiva histórica que nos auxilia a olhar de modo mais acurado para o momento atual. A autora perscruta a epidemia de cólera na Belém do Grão-Pará do século XIX, administra habilmente as precárias fontes sobre "cor/raça" e etnia e fornece um mapa complexo da desigualdade social que se abatia sobre as "gentes de cores".

Ana Teresa Venancio investe no universo conceitual do renomado psiquiatra Juliano Moreira. Sua análise traz contribuições para um campo pouco explorado contemporaneamente, que é o intercruzamento entre "raça", doença mental e sexualidade na obra de autores clássicos da psiquiatria brasileira. Autores que produziram convenções discursivas, mas cuja origem não mais detectamos e que merecem ser exploradas.

Moutinho fecha esta coletânea convidando o leitor a adentrar um outro universo de relevância fundamental na construção de certas "estruturas de sentimentos e referências" (Cf. SAID, 1995). A autora analisa em seu trabalho dois momentos paradigmáticos da obra de Jorge Amado. A partir de dois casais "inter-raciais", Amado veicula (e produz) idéias da ciência e da sociedade brasileira da época, acerca das relações entre negros e brancos, nação, sexualidade, gênero, classe e erotismo.

No conjunto de textos que ora se apresenta, vemos como as identidades disciplinares produzem, às vezes, fronteiras enganosas. Este número de Physis é uma oportunidade de buscarmos trabalhar o intercruzamento entre "raça", sexualidade, gênero, doença mental e os agravos na saúde em uma perspectiva histórica e contemporânea, sem apenas pensá-las como uma soma de discriminações - na lógica das sujeições combinadas -, como há tempos já havia enfatizado Verena Stolcke (1991). Essa inter-relação delineia, ora de modo explícito, outras vezes obscurecido, a análise de diversos autores que se debruçaram sobre os principais problemas no país. As análises acumuladas nesses campos e em suas interfaces em construção permitem explorar aspectos empíricos e teóricos desse intercruzamento, bem como dar visibilidade a estudos que já têm incorporado a interseccionalidade como estratégia heurística. 


\section{Referências}

AZEVEDO, T. Democracia racial. Petrópolis: Vozes, 1975.

FOUCAULT, M. História da sexualidade: a vontade de saber. Rio de Janeiro: Graal, 1977.

FRY, P. O que a Cinderela Negra tem a dizer sobre a "política racial no Brasil". Dossiê Povo Negro - 300 anos, Revista da USP, n. 28, p. 122-135, 1996.

LÉVI-STRAUSS, C.; ERIBON, D. De perto e de longe. Rio de Janeiro: Nova Fronteira, 1990.

MOUTINHO, L. Razão, "cor" e desejo: uma análise dos relacionamentos afetivo-sexuais "inter-raciais” no Brasil e na África do Sul. São Paulo: Unesp, 2004a.

. Condenados pelo desejo? Razões de Estado na África do Sul. Revista Brasileira de Ciências Sociais. São Paulo, v. 19, n. 56, p. 95-112, outubro/2004b. Disponível também na World Wide Web: <http://www.scielo.br/ s c i e lo.ph p ? s c ri p t $=\mathrm{s} \mathrm{ci}_{-}$art t e x t \& p i d = S 0102 69092004000300007\&lng=pt\&nrm=iso>.

. Considerações sobre violência, gênero e cor em Rio das Pedras. In : BURGOS, M. (Org.). A utopia da comunidade: Rio das Pedras, uma favela carioca. Rio de Janeiro: PUC-Rio, 2002.

NOGUEIRA, O. Preconceito racial de marca, preconceito racial de origem. In: . Tanto quanto branco: estudos de relações raciais. São Paulo: Queiroz Editora, 1985.

RABINOW PAUL. Artificialidade e Iluminismo: da sociobiologia à biossociabilidade. In: . Antropologia da razão. Rio de Janeiro: Relume Dumará, 2002. p. 135-157.

SAID, E. Cultura e imperialismo. São Paulo: Companhia das Letras, 1995.

STOLCKE, V. Sexo está para gênero assim como raça para etnicidade? Estudos Afro-Asiáticos. Rio de Janeiro, v. 20, p. 101-119, 1991.

PROGRAMA DAS NAÇÕES UNIDAS PARA O DESENVOLVIMENTO. Organização Pan-Americana da Saúde. Subsídios para o Debate. Política Nacional da População Negra: uma Questão de Eqüidade. Brasília: OPAS, UNDP, UNFPA, Unicef, Unesco, UNDCP, Unaids, Unifem, 2004. 